\title{
Alagoas e a Escrita de si mesma e da sua Gente No Século XIX: Entre Silêncios, Cabanos, Matas e Censos Demográficos
}

Janaina Cardoso de Mello*

Universidade Federal de Sergipe

\begin{abstract}
Resumo: Alagoas inaugura sua narrativa histórica sobre si mesma a partir do silêncio sobre eventos destoantes da visão de "sociedade harmônica" e "sem contradições sociais ou econômicas" que deseja firmar para a posteridade. Contradizendo essa imagem, as tentativas de consolidação de um novo grupo de poder central e local, durante o período regencial, que em suas atitudes políticas feriam costumes enraizados em práticas clientelistas, a perspectiva do acesso a armamento e a visibilidade de brechas para demonstrar sua insatisfação enquanto as elites combatiam entre si fez emergir nas matas de Alagoas e Pernambuco os Cabanos liderados por Vicente Ferreira de Paula.
\end{abstract}

Palavras-chaves: Cabanada; demografia; política; historiografia.

Abstract: Alagoas opens its historical narrative about itself from the silence on events clashing with the vision of "harmonious society" and "without economic or social contradictions" that wants to sign for posterity. Contradicting that image, attempts to consolidate a new group of central and local power, during the Regency period in wich political attitudes hurt customs rooted in clientelist practices, the prospect of acess to weapons and visibility of paths to show their dissatisfaction while elites fighting each other has created in the forests of Alagoas and Pernambuco the Cabanos led by Vicente Ferreira de Paula.

Key-words: Cabanada; demographics; politics; historiography.

\section{Aporte teórico}

O presente artigo ao tratar de Alagoas no Império e também da Guerra dos Cabanos se aproxima da vertente de pensamento de Dirceu Lindoso ${ }^{1}$ no que se refere ao corte temporal e caminhos metodológicos da análise do discurso, embora não se configure no campo da semiótica. No entanto, diverge dos três autores centrais da discussão historiográfica ${ }^{2}$ sobre o tema uma vez que sustenta a tese de "negociação e formas de interpretação diferenciadas" em oposição à idéia de contradição da práxis no processo de assimilação do discurso "restauracionista" pelos cabanos. Fundamenta-se tal proposta na idéia da "economia moral dos pobres" pensada por Edward Palmier Thompson ${ }^{3} \mathrm{e}$ "formas de resistência cotidiana" apontadas por James C. Scott. ${ }^{4}$

\footnotetext{
"Doutora em História Social pela UFRJ com a tese "O medo da guerra eterna: resistência e negociação na Cabanada (Pernambuco - Alagoas, 1832-1850) e suas interfaces com a guerrilha absolutista em Portugal" (2009); Professora Adjunta I da área de Cultura Histórica do Núcleo de Museologia na UFS.

${ }^{1}$ LINDOSO, Dirceu. A utopia armada. Rebeliões de pobres nas matas do Tombo Real (1832-1850). Rio de Janeiro: Paz e Terra, 1983.

2 A saber: Dirceu Lindoso. Op. cit, Décio Freitas com Os guerrilheiros do Imperador. Rio de Janeiro: Graal, 1978 e Manuel Correa de Andrade em A guerra dos cabanos. Rio de Janeiro: Conquista, 1965.

${ }^{3}$ THOMPSON, E. P. Costumes em Comum. São Paulo: Cia. das Letras, 2005.

${ }^{4} \mathrm{Cf}$. SCOTT, James Scott. Weapons of the weaks. Everyday forms of peasant Resistance. New Haven and London: Yale University Press, 1985; Domination and the Arts of Resistance: Hidden Transcripts.
} 
Quando se defrontando com as situações de mudanças políticas e econômicas as tradicionais práticas sociais de reciprocidade, mesmo numa relação de sujeição, são rompidas e não se garante a mínima subsistência alimentar possível aos mais pobres. Nesse contexto, insurgem-se as multidões - utilizando-se muitas vezes de um pano de fundo conservador baseado nas relações clientelísticas com os proprietários locais e/ ou em pregações religiosas - para reiterar as relações costumeiras. Dessa forma:

A "economia moral" se define, em termos de relações de classes, como a forma (ou o meio) em que estas relações são "negociadas" e mostranos "como a hegemonia não é simplesmente imposta (ou contestada), mas é articulada no dia-a-dia de uma comunidade e pode ser sustentada somente por concessão e paternalismo [patronage] nos tempos bons e por atitudes de proteção nos tempos ruins".

Assim, a despeito das clivagens econômicas, políticas, étnicas e sociais que atravessam as classes são feitas alianças em torno da expectativa da obtenção de benefícios que coletivos ou individuais, numa adaptação pragmática dos despossuídos à realidade na qual subsistem combinando sua necessidade material a uma resistência que pode se dar pelo enfrentamento aberto, violento das revoltas armadas [sendo o acesso a essas armas possível justamente pela política de aliança entre os diversos segmentos sociais] e/ ou através de processos sorrateiros onde os pobres do campo invadem fazendas para libertar escravos, ocupam parcelas territoriais para efetivar seus roçados de milho e mandioca desafiando as relações de propriedade, infiltram-se no exército legalista como "traidores de seu grupo de origem" para repassar informações equivocadas sobre os rebeldes em guerra, atuando em guerrilhas de ataques e recuos, tornando algumas vezes inócuas as políticas por aqueles detentores de uma superioridade técnica, política e econômica.

Os próprios discursos utilizados revelam não uma "ausência pura e simples de consciência de classe" nos pobres do mundo rural, mas a compreensão das relações de dominação a partir do desenvolvimento de 
interações sociais cotidianas, onde são realizadas dramatizações do comportamento público e político, com jogos de duplo sentidos em falas que apreendem eufemismos, afirmações e unanimidades num contexto de valores e insígnias de poder, muitas vezes subvertidos para atender aos interesses dos mais fracos.

Para além de uma noção de política em bases marxistas-leninistas, o fio condutor que rege esse trabalho busca associar a noção de política com as práticas culturais em voga, sem, no entanto romantizar a resistência adotada pelos pobres das matas, uma vez que estes são sujeitos de seu tempo inseridos em uma determinada cultura política que também os forja em atitudes, em grande parte não alterando substancialmente as relações de dominação, no entanto revelando a possibilidade da flexibilização e instabilidade da hegemonia dominante a partir do conjunto de pressões que a condicionam. Por isso:

sobretudo porque sofriam a constante pressão desorganizadora dos
grupos governantes e dominantes dessas sociedades que os
revoltosos careciam de representação política no nível do governo,
quer a demandassem e lutassem por ela quer não. Sob essas
condições, privados de direitos mínimos institucionalizados e
politicamente subalternos, as sublevações episódicas e dispersas
desses grupos tornavam-se praticamente a sua defesa única e eficaz;
ou, ao menos, em tais situações, eles eram levados a acreditar que
assim o fosse.

No livro sobre O período das Regências (1831-1840) ${ }^{7}$, Marco Morel concebe algumas proposições significativas para o movimento cabano ao contestar a tese de manipulação unilateral, aventando a possibilidade desta ser uma via de mão-dupla, imersos que estavam os agentes desse processo no mesmo universo de códigos e relações sociais. Expõe um movimento de caboclos, trabalhadores pobres, índios e escravos em luta contra a escravidão e as injustiças sociais na mesma região onde dois séculos antes existiram os quilombos de Palmares.

Nesse sentido torna-se referência essencial a esse trabalho a linha de pensamento de Marco $\mathrm{Morel}^{8}$, sobre a proximidade que existe entre "rebelar

\footnotetext{
6 PAMPLONA, Marco A. A historiografia sobre o protesto popular: uma contribuição para 0 estudo das revoltas urbanas. In: Revista Estudos Históricos, Rio de Janeiro, n 17, 1996.pp. 5-6.

${ }^{7}$ MOREL, Marco. 0 período das regências (1831-1840). Rio de Janeiro: Zahar, 2003. p.59-61

$8 \mathrm{lbidem}$, ibid.
} 
e revelar", isto é, de que episódios como a Cabanada geram ações e reações que, por sua vez, geram documentações e permitem, muitas vezes, estudar situações extremadas de conflitos e impasses de uma sociedade. E durante esse processo simbiótico o autor concebe ainda que "as rebeliões são momentos nos quais determinadas práticas, propostas e agentes históricos ganham maior visibilidade, marcam os rumos dos acontecimentos e imprimem presença nos registros históricos, ainda que de forma fugaz ou explosiva". 9

Para além dos enfoques tradicionais referindo-se à primeira metade do século XIX como "caótica" ou "anárquica", o estudo desse tema dispõe-se a empreender uma discussão que insira a Cabanada no diálogo com as novas vertentes historiográficas proporcionadas pelos trabalhos de historiadores como Marco Morel, Marcello Otávio Basile, Gladys Sabina Ribeiro, Marcus Carvalho, dentre outros.

\section{O limiar de tudo nas Alagoas...}

Alagoas inaugura sua narrativa histórica sobre si mesma a partir do silêncio sobre eventos destoantes da visão de "sociedade harmônica" e "sem contradições sociais ou econômicas" que deseja firmar para a posteridade. No Opúsculo da Descripção Geographica de 1844, assinado anonimamente por Hum Brasileiro, porém vinculado à pessoa de Antonio Joaquim de Moura, prevalecem os interesses sociais dos senhores de engenho e ricos comerciantes $^{10}$. De acordo com Dirceu Lindoso:

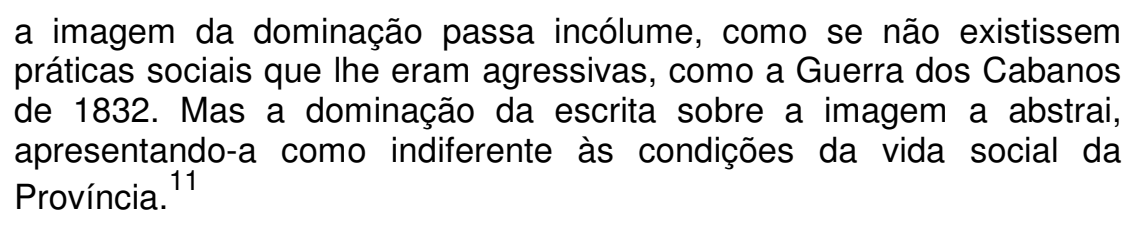

Entretanto, a visão de "barbárie", "atraso" e manipulações de origens diversas personificou a imagem do sertão, enquanto espaço físico onde alguns grupos humanos constroem suas relações sociais, e, por conseguinte os

\footnotetext{
9 Ibidem, p.51.

10 Cf. LINDOSO, Dirceu. Interpretação da Província. Estudo da cultura alagoana. Maceió: EDUFAL, 2005, p.37.

11 Ibidem, p.38.
} 
movimentos contestatórios advindos das tensões e contrastes desta espacialidade.

A historicidade dessa região remonta a tempos primeiros que subjazem no século XVII quando o projeto colonizador português era uma realidade conflitante com a presença holandesa em Pernambuco. Nesse sentido, há uma necessidade premente de se revisitar as memórias de Adriano Verdonk, escritas em 1630, traduzidas por Alfredo de Carvalho para a revista do Instituto Histórico, Arqueológico e Geográfico de Pernambuco (IHAGP). Nesta rememoração, o autor inicia seu relato referente à descrição da espacialidade das Alagoas ressaltando as águas do Rio São Francisco, os povoados e engenhos existentes ás margens deste. Chama a atenção para a inatividade das moendas e a grande quantidade de gado que de fato constituiria a real fonte de riqueza dos habitantes dessa região. Sua narrativa ainda aponta para o plantio de gêneros alimentícios:

\begin{abstract}
Os moradores plantam alli grande quantidade de mandioca e a maior parte da farinha que vem para Pernambuco é desta procedência; outrosim planta-se neste lugar muito fumo e prepara-se considerável porção de carne seca que toda é trazida para aqui e promptamente vendida; alem destes viveres produz a terra muitos outros gêneros alimentícios de que se nutrem os habitantes tanto de dentro como de fora da cidade; os moradores desta região penso que são mais affeiçoados aos hollandezes do que à gente da sua nação, porque quase todos são criminosos e gente insubordinada ${ }^{12}$.
\end{abstract}

Esta territorialidade - vinculada a Capitania de Pernambuco - à qual se refere o autor compreenderia posteriormente a denominação de Santa Maria Madalena da Alagoa do Sul (que na contemporaneidade configura o município alagoano de Marechal Deodoro). O plantio de mandioca indica uma cultura muito marcada pela presença indígena na região, constituindo-se essa raiz no elemento base na alimentação da quase totalidade da população do norte do país dentre seguimentos abastados (grandes proprietários e seus familiares) e aqueles excluídos de um cotidiano de privilégios econômicos, como moradores e lavradores (brancos e mestiços pobres), índios e escravos. Ainda ressalta-se a utilização da carne seca (charque) que junto a outros gêneros alimentícios

\footnotetext{
12 Descrição das Capitanias de Pernambuco, Itamaracá, Parahyba e Rio Grande (Memória apresentada ao Conselho Político do Brasil por Adriano Verdonk, em 20 de maio de 1630) In: Revista do Instituto Histórico, Arqueológico e Geográfico de Pernambuco, n5 55, Recife XXXIX, 1901, p.217.
} 
representam a configuração de um mercado interno de circulação de bens advindos da existência de uma cultura agrícola de roçados e investimento na pecuária no interior da espacialidade.

Contudo, a detração com a qual é tratada a população dessa área, em função de sua suposta articulação com os invasores holandeses, vincula um juízo de valor depreciativo ("criminosos", "gente insubordinada") se aplicaria mais tarde à escrita alagoana constituída no século XIX, quando a linguagem referenda discursos de "patologia social" no povo alagoano envolvido em movimentos contestatórios. Mesmo as correspondências militares oficiais que tratavam de informar o desenvolvimento da guerra dos cabanos em Pernambuco e Alagoas intitulava os envolvidos nesse movimento social como "faccinoras", "rebeldes", "criminosos", "bárbaros", "selvagens", dentre outras denominações de caráter pejorativo.

O mesmo autor continua seu relato descrevendo o povoado de Porto Calvo, também contando com poucos habitantes, tendo no gado sua principal fonte de riqueza, mas também se ocupando do plantio de fumo, da fabricação de farinha, da pesca de "capatões" (espécie de pescado da região), além da existência de engenhos que produziam um pouco de açúcar. Mas uma vez indicava a comercialização desses produtos em Pernambuco ${ }^{13}$.

Próximo a Porto Calvo, encontrava-se a espacialidade conhecida como Una, onde seus moradores criavam gado, cultivavam mandioca e milho, mas também o fumo, o feijão, as favas e outros cereais, além de pescarem e venderem seus alvitres em território pernambucano. Também há o relato da existência de uns 4 ou 5 engenhos produtores de açúcar na vizinhança. A descrição da população, no entanto, ainda se prende a um juízo crítico de valor com base numa qualificação étnica negativa: "os moradores também não são numerosos, de sorte que penso que do rio de S. Francisco até ahi, no espaço d'umas 20 milhas, podem morar cerca de 500 a 600 homens, quase todos mestiços e gente muito má,"14.

Não muito longe da localização de Una encontrava-se Serinhaem, cujas características apontavam diferenças significativas com relação aos demais já descritos anteriormente. Nesse povoado é descrita uma pobre participação

13 Ibidem.

14 Ibidem, p.218. 
junto à criação de gado, uma vez que os moradores dedicavam seu tempo à produção de açúcar, possuindo esta região entre 12 e 13 engenhos produzindo de 6 a 7,000 arrobas, chegando-se a carregar entre 100 a 110 caixas nas barcas que o transportam pelo rio. A descrição referente aos habitantes da terra apresenta-se mais tolerante, porém ainda com tons de desqualificação social baseada na posse de bens econômicos:

No mesmo povoado e nas proximidades moram muitos Albuquerques,
grandes nobres segundo pensam, mas, na realidade gente pobre e
indigente, e ao todo póde alli haver uns 500 habitantes, que plantam
muita mandioca, fumo e toda a casta de cereaes e pegam muito peixe;
há também ali algum pau-brasil e a mesma jurisdição de Serinhaem é
um sitio muito aprazível para morar-se. ${ }^{15}$

$\mathrm{Na}$ espacialidade circunvizinha encontra-se Ipojuca, onde residem perto de 600 habitantes, sendo muitos destes descritos como "gente rica", e o lugar como de agradável moradia. Relatam-se a existência de 13 ou 14 engenhos produtores de grande quantidade de açúcar, além de referir-se à escassa produção de farinha, fumo e peixe dos quais os moradores locais não se alimentam, sendo esta a razão do descaso com esses gêneros. A importância do curso de águas nessa espacialidade, usada para o transporte do açúcar ao Recife é ressaltada, bem como a presença de canhões para a defesa contra os inimigos na foz do rio Ipojuca ${ }^{16}$.

Embora alguns cronistas setecentistas ${ }^{17}$ tenham delineado em suas descrições o espaço do "sertão bravio", por ocupar este tipo de paisagem a maior parte das áreas no Nordeste com seu clima mais seco, relevo uniforme, tendo como vegetação a caatinga e por isso uma ocupação humana mais pulverizada, nem sempre essa classificação correspondia a geografia real, pois foi na zona da mata que se desenvolveu a cultura da cana-de-açúcar, do cacau e do fumo devido ao seu clima quente e úmido, onde as grandes propriedades estabeleceram-se como frutos da doação de sesmarias. $^{18}$ Mas a predominância de uma generalização do uso do termo "sertão" nos séculos XVII e XIX difunde-se, segundo Marcus Carvalho, em função da existência de:

\footnotetext{
15 Ibidem.

16 Ibidem, pp. 218-219

17 Cf. Diário da Viagem do Capitão João Blaer aos Palmares em 1645 In: CARNEIRO, Edison. O Quilombo dos Palmares. Coleção Brasiliana vol. 302. São Paulo: Editora Nacional,1947.

18 MONTEIRO. Hamilton de Mattos. Nordeste insurgente (1850 - 1890). São Paulo: Brasiliense, 1981. pp. 9-11.
} 
matas inconquistadas, tanto devido ao terreno acidentado, como por necessidade, pois os engenhos não poderiam operar sem lenha. Além disso, a própria coroa incentivava a preservação das madeiras nobres, próprias para construção naval. Essa madeira também tinha valor comercial para os negociantes locais. Era nessa floresta que vivia a "gente das matas". 19

Não era a distância ou certo isolamento que alcunhava essas matas de "sertões", mas a temeridade de trilhar seus caminhos com terrenos acidentados, o desconhecimento de seus recônditos profícuos em terras férteis, mas de complexo acesso e a dificuldade de conquistá-la, mesmo possuindo uma superioridade colonizadora marcada pelo ferro e pelo fogo. ${ }^{20}$

Todavia, aproveitando-se das características ecológicas e sociais locais dos sertões, o recrutamento de povos indígenas para a composição de grupos armados pró-portugueses em confrontos contra estrangeiros ou negros quilombolas era algo costumeiro na América portuguesa, principalmente com os sucessos obtidos contra os batavos em Pernambuco, quando a partir de 1631 utilizou-se de uma tática de "guerra lenta", mantendo-se o impasse e o desgaste das forças inimigas, logo cedendo espaço à estratégia militar da "guerra do Brasil" ou "guerra brasílica" - fomentada por Matias de Albuquerque - compondo-se num "sistema de emboscadas", onde:

\begin{abstract}
com uns trinta ou quarenta homens (vários deles índios "frecheiros", isto é, hábeis com as flechas), estas guerrilhas deviam, também, atormentar o inimigo e desbaratar-Ihe os postos e comunicações. (...) não se tratava apenas de fazer a guerra, mas também de sustentar quem a fazia. As guerrilhas, ao zelarem pela várzea, impedindo a entrada dos holandeses, cuidavam da produção dos alimentos e do açúcar, o combustível da guerra. Os portugueses, segundo o memorial de João Cardoso, tornavam-se invisíveis nos matos, onde eram imbatíveis. ${ }^{21}$
\end{abstract}

A percepção dessa área geográfica e seus usos tornam-se fundamentais para o entendimento do imaginário que se constrói a respeito dos participantes na guerra dos cabanos envolvendo a população do campo nas matas ao sul de Pernambuco e norte de Alagoas, entre 1832 e 1835. Índios aldeados, brancos

\footnotetext{
19 CARVALHO, Marcus J. M. de. A Mata Atlântica: Sertões de Pernambuco e Alagoas, sécs. XVII-XIX. In: Clio Revista de Pesquisa Histórica - nº. 25-2, Pernambuco: EDUFPE, 2007. p. 250.

20 Ibidem, p. 252.

21 PUNTONI, Pedro. A guerra dos bárbaros. Povos indígenas e a colonização do sertão nordeste do Brasil, 1650 - 1720. São Paulo: Hucitec, 2002, p.187.
} 
e mestiços lavradores e moradores nas periferias dos engenhos e negros fugidos dos plantéis, organizados em mocambos, travaram com as forças militares provinciais um confronto com táticas de guerrilha herdadas dos tempos das invasões holandesas na região. Os ataques e recuos para as matas com "trilhas quase intransitáveis" tornavam a repressão governista ineficaz.

A moradia em cabanas muito pobres nomeou os participantes desse movimento social. A princípio chamados de facínoras e rebeldes e a partir de 1833 e 1834 as cartas militares já os denominam "cabanos". Conforme afirma o pesquisador Dirceu Lindoso:

No Opúsculo de Discrição Geographica, de 1844, atribuído a Antonio Joaquim de Moura, os Cabanos são apodados de 'matilha de feras desumanas mui bem armada', desse modo se iniciando na historiografia estamental o discurso historiográfico que encerrou as realidades insurrecionais cabanas num cárcere textual. ${ }^{22}$

Essa visão compreende um olhar sobre o homem sertanejo a partir da representação que a natureza lhe confere, dessa forma, ao conceber o sertão como um lugar longínquo, isolado, que destoa do ambiente de conformação social da normalidade e circulação de famílias, enquanto um local cotidiano de vivência e trânsito, esta espacialidade encerra símbolos de estranheza, malefícios e não-aceitação por parte dos homens ditos "civilizados".

Categoria essa que contrapõe em dados discursos a "negatividade" do sertão à "positividade" do meio urbano ou rural controlado pelos segmentos sociais privilegiados de dada região. Revelando, portanto, uma classificação normativa centrada em modelos preestabelecidos de uma geografia e uma tipologia humana em conformidade com padrões que indicam os "tipos" menos qualificados à apreciação pública, ou seja, as "gentes perigosas" que ameaçam os partícipes respeitáveis da sociedade no que diz respeito à suas propriedades.

Assim, o sertão configura a morada de "outros", ou seja, de povos vistos como exóticos, diferentes, cuja cultura ou etnias diversas os alijam da aprovação própria dos tipos nacionais que contribuem para a edificação da nação com a produção de riquezas e formas de sociabilidade variadas.

\footnotetext{
22 LINDOSO, Dirceu. A utopia armada...op. cit. p.17.
} 


\begin{abstract}
Mesmo quando identificado como um nacional, o sertanejo é definido como um segmento diferente, um tipo exótico ou arcaico dotado ou não de alguma positividade (conforme o discurso considerado). Depositário dos males inerentes à mistura das raças, para alguns; produto positivo dessa miscigenação adaptado às condições adversas do meio, para outros; portador dos valores autênticos do caráter nacional; fruto da degeneração advinda do isolamento e do abandono; enfim, são múltiplas as faces desse personagem desenhadas pela intelectualidade brasileira. $^{23}$
\end{abstract}

No que diz respeito ao Norte e Nordeste do país, essa imagem foi efusivamente reproduzida pelas elites locais ao buscarem-se distanciar dessa realidade pontuando uma "desigualdade" fundamental no exercício das relações de poder junto aos segmentos menos favorecidos. Entretanto, mesmo tornando clara essa marca de distinção, os mundos de escravos e senhores não se encontravam de todo apartados. Interagiam num processo de negociação de uma coexistência possível que ora mostrava-se controlado pela força da coerção e ora mostrava-se imbuído em convulsões inerentes às contradições de interesses do sistema latifundiário.

O território descrito no século XVII mais tarde, já no século XVIII, seria alvo de um relatório do capitão-geral José César de Meneses em 1774, quando o mesmo refere-se a espacialidade pernambucana como possuidora de "matas incultas" que se estendiam pela costa do mar norte de Alagoas, entre o rio Pirassinunga, cercadas por inumeráveis rios que se confrontavam com os sertões. Matas selvagens e ricas em madeira de lei, que abrigou desde o início da colonização mucambos negros. ${ }^{24}$

As mesmas matas das guerras oriundas da ocupação holandesa sobre Pernambuco, dos combates de Palmares, que cederiam espaço a Cabanada de 1832. Espaço de bosques denominados "brenhas" ou "esconderijos" para "salteadores" que usavam como estratégia de luta ataques e recuos para as matas. Essa localidade abrigava mestiços pobres, despossuídos de terras, que no espaço "inculto" abriam seus roçados de subsistência ou utilizavam-na

\footnotetext{
${ }^{23}$ LIMA, Nísia Trindade Apud MORAES, Antonio Carlos Robert. O sertão: um "outro" geográfico. In: Terra Brasilis Revista de História do Pensamento Geográfico no Brasil. Anos III-IV, n 4-5 - Território, Rio de Janeiro: 2002-2003, p.18

${ }^{24}$ RELATÓRIO DO CAPITÃO-GENERAL JOSÉ CÉSAR DE MENESES. Idéia da população da Capitania de Pernambuco e das suas anexas, extensão de suas Costas, Rios e Povoações notáveis, agricultura, número de Engenhos, Contratos e Rendimentos Reais, aumento que estes tem tido \& desde 0 ano de 1774 em que tomou posse do Governador das mesmas Capitanias o Governador e Capitaim General... In: Annaes da Biblioteca Nacional do Rio de Janeiro, vol. XL (1918). Rio de Janeiro: Oficinas Gráficas da Biblioteca Nacional, 1923, p.54.
} 
como guarida para lançarem-se furtivamente sobre engenhos e vilas nas proximidades. As matas garantiam-lhe a sobrevivência possível numa sociedade profundamente exclusora daqueles que não detinham bens. Os índios também se acercavam de um feixe de terra para dedicarem-se ao plantio e extração da madeira.

Dessa forma, constituía ainda essa espacialidade uma possibilidade alternativa de evadir-se, mesmo que remotamente, à miséria rural que se intensificou sobre os povos pobres após o término da Cabanada. Quando as matas são tomadas pelos grandes e médios proprietários de Alagoas e Pernambuco, seus bosques são derrubados para ceder espaço à extensão das plantações de açúcar ou colônias de estrangeiros, reduzindo o homem pobre que outrora sobrevivera da caça, pesca e dos frutos comestíveis dessa territorialidade a um errante sem perspectivas vindouras. Segundo a visão de Dirceu Lindoso:

a devoração das matas pelo fogo das fornalhas dos engenhos e dos roçados grandes significou a degradação da pobreza colonial, que surgira na época da conquista e ocupação, e sua conversão em miséria sesmeiro-escravista. ${ }^{25}$

Algo que para além da questão material atinge essa população em sua percepção de si mesma vinculada à natureza que a cercava e lhe conferia uma identidade singular de "pobres das matas"26. Espaços múltiplos de sobrevivência, espaço de resistência, espaço onde se desenvolviam relações sociais entre segmentos de etnias plurais e distintos status sociais no que tange à questão da liberdade ou da escravidão. Mas esse território que protegia a parte menos favorecida desde o setecentos correspondia num pólo oposto ao medo dos grandes proprietários que se sentiam ameaçados em sua condução dos destinos da região sobre terras e homens.

A terra corporificava uma fonte de renda essencial, meio através do qual se distinguiam os homens. Comportava investimentos em mão-de-obra e produtividade, bem como desse empenho decorria a lucratividade que garantia

\footnotetext{
25 LINDOSO, Dirceu. A utopia armada...op. Cit, p.93

26 De acordo com Marcus Carvalho, a concepção de "pobres das matas" ou "gentes das matas" - apelidos conferidos pelos conquistadores portugueses, proprietários de terras e cativos - designaria os povos que buscavam sua subsistência nas florestas incultas, que abrigaram por séculos de convívio forçado negros e índios, com identidades dinâmicas, plurais e divergentes, construídas num cotidiano de luta pela terra onde 0 adversário imediato poderia ter a mesma procedência étnica. In: Carvalho, Marcus J. M. de. Op. cit. pp. 251-252.
} 
a riqueza das famílias que detinham o poder econômico e político local nas regiões do norte do Brasil desde o período colonial. A elas submetiam-se aqueles que estavam alijados da condição de proprietários.

Segundo Antonio Carlos Robert Moraes: "os lugares tornam-se sertões ao atraírem o interesse de agentes sociais que visam estabelecer novas formas de ocupação e exploração daquelas paragens, ${ }^{27}$. Logo, a busca pela expansão territorial ao norte de Alagoas e sul de Pernambuco empreendida por latifundiários da lavoura açucareira aliados aos liberais conservadores que ocupavam o poder político nas duas províncias, retira do pequeno morador e lavrador que outrora ocupara esse espaço a possibilidade de manter sua subsistência. O avanço sobre as terras ocupadas por povos indígenas da região de Porto Calvo e Atalaia, amparado no recrutamento, contribui para o cerceamento da posse territorial a esses segmentos de pobres das matas.

O aldeamento indígena de Jacuípe, desde 1817, fora posto sob o controle dos brancos, impondo a participação dos indígenas na insurreição pernambucana, na Confederação do Equador e depois na sedição a Porto Calvo. Em 1823, mediante as ordens do Diretor dos Índios Inácio Pereira, os índios marcharam com pólvora molhada sob o comando do Tenente-coronel Jacinto Paes de Mendonça, colocando-se em risco de não conseguir defenderse dos bacamartes inimigos. ${ }^{28}$ Eram recrutados forçosamente a darem a vida por um Estado que não os valorizava como tal e os mantinha sob controle militar.

Manuela C. da Cunha em seus estudos sobre a questão indígena no Brasil também aborda a questão da negação da soberania das nações indígenas por parte do Estado nacional, e enfatiza que a partir do século XIX essa soberania passa a ser escamoteada e “(...) não se admite, nesse início do século XIX, que os índios possam constituir sequer sociedades dignas desse nome". 29

A escrita dos Apontamentos para a civilização dos índios bravos do Império do Brasil, de autoria de José Bonifácio de Andrada e Silva, em 1823,

\footnotetext{
27 MORAES, Antonio Carlos Robert. O sertão...op. Cit., p.14.

28 PEREIRA, Inácio. Correspondência a Junta de Porto Calvo. Jacuípe, em 08/03/1823. In: APA.

29 CUNHA, Manuela C. da Apud. MOTA, Lúcio Tadeu. 0 Instituto Histórico e Geográfico Brasileiro e as propostas de integração das comunidades indígenas no Estado nacional. In: http://www.dhi.uem.br/publicacoesdhi/dialogos/volume01/Revista\%20Dialogos/DI\%C1LOGOS09.doc (16/12/06), p.152
} 
expõe as dificuldades para a "civilização" dos índios, que, a seu ver, eram duas: primeira, a própria natureza dos índios, que eram povos "vagabundos", "guerreiros", "sem religião", não sujeitos às leis, "preguiçosos", e porque não queriam perder sua forma de vida caso entrassem para o grêmio da civilização; a segunda resultava do modo como os brancos tratavam os índios. ${ }^{30}$

As elites imperiais adotaram uma concepção de governabilidade centrada no "mito da modernidade", de superação da "situação colonial", da "ocidentalização" do mundo que incidia diretamente sobre as populações indígenas no Brasil. No ponto de vista dessas elites, os índios deveriam "civilizar-se", "modernizar-se", através da assimilação passiva das idéias propostas, ou em caso de resistência, sendo subjugados pela força militar.

Segundo Manuela Carneiro da Cunha um dos principais pontos constitutivos da questão indígena no século XIX foi o "estreitamento da arena" onde se debatiam os destinos das populações indígenas. Nos séculos anteriores havia três interlocutores (a coroa, os moradores e os padres jesuítas) com perspectivas ora aproximadas ora destoantes, enquanto no século XIX não houve "projetos ou vozes dissonantes" que divergissem do poder central. ${ }^{31}$ De acordo com a tese de integração das sociedades indígenas defendida por Lúcio Tadeu Mota:

\begin{abstract}
apesar das diferentes posições externadas pelos debates no IHGB, o objetivo final era a integração, enquadramento e sujeição das populações indígenas ao Estado nacional, fundindo-as no "povo brasileiro". Com isso, todos se harmonizavam: governo imperial e provincial, missionários, populações brancas e as elites letradas que discutiam a questão. No entanto, reafirmo o tenso debate existente entre a elite formadora de opinião sobre a forma dessa integração. $O$ IHGB foi o local privilegiado desses debates e a sua Revista o meio eficiente de difusão dessas idéias. ${ }^{32}$
\end{abstract}

Pode-se observar, que após os debates de intelectuais do Império a respeito da questão indígena e da determinação da extinção dos aldeamentos declarando a inexistência de índios no país e a conseqüente apreensão das terras outrora concedidas a estes, tornou-se mais conveniente o ocultamento da identidade indígena. A tática do silêncio ou da negação tornou-se uma defesa contra o sistema político-econômico branco que se impunha nos territórios indígenas, usando muita violência contra as populações nativas

\footnotetext{
${ }^{30}$ Ibidem.

${ }^{31}$ CUNHA, Manuela C. da Apud. Ibidem, p. 171.

32 Ibidem, p.171.
} 
através de perseguições, discriminações etc. Os discursos oficiais históricos e ideológicos terminavam por consolidar essas práticas, inibindo qualquer atitude de oposição desses indivíduos a essa poderosa hegemonia. Dessa forma, muitos "caboclos" optaram pelo anonimato e por essa alcunha que em si não os tornava nem brancos, nem índios.

Todavia, a apropriação dessa idéia de "mestiçagem" realizada pelos próprios detentores do poder político terminou por legitimar o confisco das áreas indígenas, pois uma vez que essa espacialidade não possuía mais "índios puros" não se justificava a manutenção da posse territorial por caboclos. Ao tratar da presença indígena na região alagoana onde se conflagra a Guerra dos Cabanos, Luiz Sávio de Almeida indica que:

\begin{abstract}
os índios iam sumindo, também, pela miscigenação. Chegar-se-ia ao ponto de argumentar: o tipo estava desaparecendo. A inexistência da pureza implicava na inexistência de alguém caracterizado como índio e, por conseqüência, não poderia possuir terra. Esta investida vinha de longa data, mas é suficiente citar uma correspondência do Comandante do Arraial de Atalaia, dirigida ao Governo da Capitania de Pernambuco no final do século XVIII. Afirmava que no território do arraial estavam residindo muitos brancos casados e eles desejavam servir na tropa. ${ }^{33}$
\end{abstract}

Ao término da guerra dos Cabanos, há uma tentativa de racionalizar-se a administração das Províncias, e centralizar as informações demográficas a respeito dessas a partir da realização de censos populacionais que grosso modo tratam os aspectos quantitativos e qualitativos das populações. Esses dados possibilitariam um maior conhecimento e controle sobre as áreas, principalmente aquelas recentemente envoltas em sublevações, identificando seus moradores e classificando-os por gênero, cor (incluindo-se os povos indígenas) e idade. Dessa forma, surgem divisões entre "brancos, pardos, pretos e índios" num dado momento, para mais tarde aprimorar-se essas categorias em "brancos, pardos forros, pardos cativos, pretos forros, pretos cativos". Sendo essa ultima disposição indicativa de uma pretensão maior com o detalhamento para melhor controlar os libertos e a população livre de cor em Alagoas. De acordo com Flávio Gomes, essa "ideologia da racialização" presente no século XIX, deve levar em conta que:

\footnotetext{
33 ALMEIDA, Luiz Sávio de. Memorial Biographico do Capitão de Todas as Matas. Recife: Tese de Doutorado em História /UFPE, 1995. p.9 (Capítulo 7).
} 
períodos de generalizados temores de insurreições - via boatos e denúncias - serviram também para o desencadeamento e 0 recrudescimento da repressão sobre a população negra livre, especialmente os libertos. Foram assim na Corte, em Recife, Salvador e São Luís. Mesmo as tipologias raciais construídas na imprensa, nos censos e na literatura revelam disputas por símbolos que escondiam tensões e expectativas. ${ }^{34}$

Os relatórios dos presidentes provinciais de Alagoas, a partir de 1837, mostram uma preocupação com a Lei Provincial de 9 de março de 1836 para o levantamento de mapas estatísticos e topográficos da Província, solicitando que se colocasse um ou dois oficiais engenheiros para a empreitada, ameaçando multar as autoridades que descumprissem os prazos para o fornecimento das informações exigidas pela administração. ${ }^{35}$ Todavia, um ano depois, o mesmo presidente, Rodrigo de Souza da Silva Pontes, comunica que apesar da nomeação dos referidos engenheiros, o trabalho de coleta das estatísticas não foi levado a efeito. ${ }^{36}$

Em maio de 1839, o presidente alagoano, Agostinho Neves, relata que estão prontos somente os mapas de Maceió e Penedo, aguardando o mapa geral da população da província. Justifica as dificuldades decorrentes da inexperiência neste gênero de trabalho, dizendo que os dados parciais apresentados não são exatos, mas que ele podia asseverar "que elles se aproximão á esta o mais que he possível", informando ainda que havia solicitado aos párocos a remessa da lista de óbitos, casamentos e batizados ocorridos nas suas freguesias, aos prefeitos uma relação dos crimes nas Comarcas, afirmando a existência de um mapa topográfico da Província, mas cheio de imperfeições. ${ }^{37}$

No governo provincial de Souza Mello, a ineficiência dos trabalhos nessa direção é posta às claras quando o mesmo em seu relatório de 1842 afirma: “ignoramos perfeitamente quantos habitantes tem esta Província, e como distribuídos nos diferentes Termos, e Freguesias que porção de terra cultivada, e que productos dão". Continua ainda, com uma honestidade ímpar, a expor o desconhecimento sobre dados referentes também à segurança pública, pois segundo o mesmo: "não sabemos mesmo quasi nada da parte criminal, porque

\footnotetext{
34 GOMES, Flávio, FERREIRA, Roquinaldo. A Miragem da Miscigenação In: Novos Estudos, n 80, CEBRAP, Março de 2008, p.156.

${ }^{35}$ Relatório do presidente da Província de Alagoas, Rodrigo de Souza da Silva Pontes, em 12/01/1837., p.3. In: AN

${ }^{36}$ Relatório do presidente da Província de Alagoas, Rodrigo de Souza da Silva Pontes, em 06/01/1838., p.6. In: AN

${ }^{37}$ Relatório do presidente da Província de Alagoas, Agostinho Neves, em 09/05/1839., pp. 18-19. In: AN.
} 
ignorão-se muitos assassinatos, e outros crimes comettidos pelo interior", também diz não estar ciente do valor pago em impostos de gêneros não exportados "porque a mor parte desta renda, ou não era cobrada por desleixo dos collectores, ou por suas mãos se escoava...", indicando a continuidade da corrupção na província. ${ }^{38}$ Mesmo assim ainda tentou organizar um mapa da população e das casas com auxílio de algumas autoridades.

Ainda em 1846, na presidência de Campos de Melo, determinava-se que se cuidasse da estatística da Província, solicitando que fosse confeccionada uma lei para organizá-la e demonstrando suas vantagens, definindo-a como:

não sendo ella outra coiza mais que a enumeração de tudo o que constitue a força de hum paiz, bem como a população, a agricultura, industria, condição dos indivíduos, educação, rendas e despesa pública, força militar, distribuição da propriedade, etc. ${ }^{39}$

No ano de 1847, um mapa foi organizado pelo Chefe de Polícia, sendo os dados publicados junto ao relatório do presidente da Província de Alagoas, Antonio Manoel de Campos Mello. Nele estava especificado o quantitativo total populacional de 207.294 pessoas, subdividindo-se em 56.199 brancos, 6.733 índios, 12.451 pretos livres, 30.928 cativos, 9.236 pardos livres, 8.747 pardos cativos, sendo que 22.366 pessoas sabiam ler, 18.343 eram homens e 4.023 eram mulheres. ${ }^{40}$

Tentava-se instituir um saber técnico, dentro de uma "linguagem oficial" e homogênea definida por um Estado "cujo poder dependia desse tipo de prática e representação em torno da ordenação da população".41 Todavia, essa tentativa de burocratização esbarrava na resistência, despreparo e oposição tão peculiares à realidade política vivenciada em cada província.

\section{Considerações Finais}

No que tange especificamente a guerra cabana, falar na participação de proprietários de terra, índios, lavradores e escravos em uma mesma mobilização pressupõem perceber os interesses diferenciados, uma vez que

\footnotetext{
38 Relatório do presidente da Província de Alagoas, Souza Mello, em 04/02/1842, p.21. In: AN.

39 Relatório do presidente da Província de Alagoas, Antonio Manoel Campos Melo, em Março de 1846, p.30. In: AN.

40 Relatório do presidente da Província de Alagoas, Antonio Manoel Campos Melo, em 15/03/1847, p.25. In: AN.

41 LIMA, Ivana Stolze. Cores, marcas e falas. Sentidos da mestiçagem no Império do Brasil. Rio de Janeiro: Arquivo Nacional, 2003, p.91.
} 
cada grupo possui uma historicidade própria. Enquanto os primeiros reivindicam a continuidade dos privilégios dos quais desfrutavam junto à administração política e das relações de mando e propriedade de terras e cativos; índios e lavradores buscavam garantir vantagens mínimas de acesso a terra nos aldeamentos ou arrendamentos, subsistência mínima na produção de gêneros alimentares em seus roçados e liberdade, ainda que limitada, mas que os tornava "cidadãos" aos olhos do Estado em vários momentos; enquanto para os escravos do período um couto nas matas era a garantia de um offstage, ou seja, estar fora de um palco cujo cenário remetia-se a senzala, ao trabalho exaustivo nas plantações, às chibatadas e outros suplícios físicos. $O$ que os unia, tendo em vista motivações tão díspares? As tentativas de consolidação de um novo grupo de poder central e local que em suas atitudes políticas feriam costumes enraizados em práticas clientelistas, a perspectiva do acesso a armamento e a visibilidade de brechas para demonstrar sua insatisfação enquanto as elites combatiam entre si.

Enquanto as elites governistas viam nos cabanos os "salteadores", "ladrões" e "facinorosos", representando-os através de uma linguagem de imprensa violenta e pejorativa, os rebeldes apreendiam o momento como uma via para responder aos tratamentos considerados injustos como as expulsões de seus arrendamentos e da zona da mata, desbastada para o avanço da empresa açucareira. ${ }^{42}$

Luiz Sávio de Almeida considerou a presença do absolutismo e da inserção das idéias da facção restauradora, algo circunstancial, conferindo a essência do movimento cabano à figura de Vicente Ferreira de Paula. ${ }^{43}$ Todavia, as cartas de Vicente de Paula ${ }^{44}$, mesmo que escritas em meio à uma condição de semi-analfabetismo, revelam que o mesmo estava ciente das concepções restauradores e acreditava de fato que o retorno de D. Pedro I

\footnotetext{
42 De acordo com Marcus Carvalho: "the elites emphasized that the peasantry who rose up did not do it for ideology, but to steal cattle, horses and food. The authorities did not understand peasant appropriation was part of the game. In the peasants eyes, stealing was at least as legitimate as eviction", ou seja, "(...) as elites enfatizaram que 0 campesinato, que se levantou, não fez isso por ideologia, mas para roubar gado, cavalos e comida. As autoridades não entendiam que a ação camponesa era parte do jogo. Aos olhos dos camponeses, roubar era pelo menos tão legítimo como despejo". (Tradução Livre). In: CARVALHO, Marcus J. M. de. Hegemony and rebellion in Pernambuco (Brazil), 1832-1835. Tese de Doutorado. Illinois: University of Illinois, 1985, p.275.

${ }^{43}$ ALMEIDA, Luiz Sávio de. Memorial Biográfico de Vicente Paula, o capitão de todas as matas. Guerrilha e sociedade alternativa na mata alagoana. Maceió: EDUFAL, 2008.p. 269.

${ }^{44}$ Carta de Vicente Ferreira de Paula à Pinto Madeira Cf. Sessão de Manuscritos, I-32, 11, 2, em 08/10/1833. In: BN e Ministério da Guerra, IG' 94, em 09/01/1833 In: AN.
} 
traria benefícios para ele e seus seguidores. Embora, é claro que sua apreensão da perspectiva restauracionista fosse diversa da visão de proprietários como Torres Galindo ou João Batista de Araújo. Ele não era um "guerrilheiro do Imperador" como foi intitulado por Décio Freitas ${ }^{45}$, mas ele circulou pelas residências de importantes políticos alagoanos após a finalização da guerra cabana, como foi demonstrado por Dirceu Lindoso ${ }^{46}$ e Manuel Correia de Andrade ${ }^{47}$.

Designar Vicente Ferreira de Paula, como "caudilho", como o faz Luiz Sávio de Almeida, remete a uma categorização além de equivocada, credora de concepções tradicionalistas que terminam por desqualificar sua ação e /ou "demonizá-lo" dentro dos preceitos da atividade política local, além de promover um esvaziamento do significado da participação das massas anônimas que estavam em seu entorno, como se houvesse um jogo de inversão, onde essas estariam sendo permanentemente manipuladas ou por um senhor de engenho ou por líder popular. Há que não se confundir liderança com caudilhismo, ou haverá a reprodução das armadilhas de reafirmação das leituras tradicionais feitas anteriormente sobre 0 movimento cabano, enfatizando-os como "uma matilha de cães selvagens" ou "ignorantes aliciados por um monstro,48.

A idéia de "caudilho" surgida na América Latina teve como objetivo a denominação de líderes conservadores que ascendiam o poder através de golpes de Estado e implantavam ditaduras personalistas. Na mioria dos casos, eram militares ou grandes proprietários de terras. A emergência de "caudilhos" era favorecida pela própria estrutura social das ex-colônias espanholas e portuguesas, nas quais latifundiários detinham grande poder político. ${ }^{49}$

Embora reunisse algumas características corporificadas em seu carisma pessoal, liderança autoritária, exercício da violência, apego conservador aos valores tradicionais da religião, Vicente Ferreira de Paula jamais foi um latifundiário e muito menos possuiu chances reais de tomar o poder provincial

\footnotetext{
${ }^{45}$ FREITAS, Décio. Os guerrilheiros...op. cit.

${ }^{46}$ LINDOSO, Dirceu. A utopia... op. cit.

47 ANDRADE, Manuel Correia de. A guerra... op.cit.

${ }^{48}$ ESPÍNDOLA, Thomaz do Bom-Fim. A Geografia Alagoana ou descrição física, política e histórica da província das Alagoas. Maceió: Edições Catavento: 2001 [1871].

${ }^{49}$ OLIVERI, Mabel. In: BOBBIO, Noberto. Dicionário de política. 5. ed. Brasília, Universidade de Brasília,1993. p.157.
} 
via um golpe militar à moda do ocorrido em ex-colônias espanholas. Deve-se atentar ainda, para o fato de que a política de alianças é uma parte fundamental do jogo político e a liderança de Vicente Ferreira de Paula só encontrou aceitação entre o contingente popular cabano em função da própria situação de vilipêndio na qual encontravam-se. Os "indigentes da sociedade liberal moderada" viram uma possibilidade de fazer ressoar suas demandas e quem sabe, obter algum ganho durante a revolta contra aqueles que se impunham à sua sobrevivência. O uso da violência nesse sentido deixava de ser uma prerrogativa Estatal, para o ser também dos populares.

Ressalte-se também a participação do clero regular como integrante do movimento cabano ou dos governos provinciais como instrumentos de dissuasão. Essa participação de religiosos em conflitos políticos era algo tradicional em Pernambuco e Alagoas desde os primórdios oitocentistas, assim como sua heterogeneidade de posicionamento, ora 'rebelde', ora 'conservador'. Para os cabanos que defendiam em seu discurso a "santa religião católica, o trono e o altar" a presença de padres para a realização de missas e conferência de sacramentos religiosos era parte integrante de sua formação cultural tradicional, que muitas vezes só encontrava alívio das mazelas do cotidiano através das orações. Mesmo assim, mais uma vez, perceber a religião como alienadora do contingente cabano contradiz as próprias ações desse que em vários momentos não se enquadravam na perspectiva da igreja, como exemplo, na adoção do uso matrimonial "despique" durante e após a guerra cabana, considerado uma "imoralidade e um abuso de natureza anticristã" pelo frei José Plácido de Messina. ${ }^{50}$

Possuindo interesses diferenciados, com as anistias promovidas pelo governo, os cabanos índios e lavradores negociaram benefícios como vestimentas, medicamentos, alimentos, instrumentos de cultivo e conseqüentemente terras para a agricultura. Aos escravos restava o retorno à escravidão e a venda para fora da província.

Todavia, o decréscimo da mobilização nas matas em fins de 1834 não significou, porém, o fim do cerco ou dos conflitos, pois muitos rebeldes mantiveram-se nas cercanias, havendo hostilidades entre esses e os

50 LINDOSO, Dirceu. Formação de Alagoas Boreal. Maceió: Catavento, 2000. p.158. 
proprietários de engenho que reclamavam ao governo da província de ataques de cabanos promovendo incêndios, furtos e libertação dos escravos.

Ao olhar atentamente para o início e o fim da guerra cabana, percebe-se que esta se tornou, em seus últimos dias, uma revolta de negros papa-méis, de escravos, resistindo da forma que lhes era possível ao sistema escravista em curso, utilizando para isso a resistência cotidiana, lenta e contínua, que se não fazia ruir os pilares dos engenhos, ou colocava em xeque as relações de poder, ao menos causava prejuízos aos proprietários locais.

\section{Referências Bibliográficas}

1. ALMEIDA, Luiz Sávio de. Memorial Biographico do Capitão de Todas as Matas. Recife: Tese de Doutorado em História /UFPE, 1995.

2. Memorial Biográfico de Vicente Paula, o capitão de todas as matas. Guerrilha e sociedade alternativa na mata alagoana. Maceió: EDUFAL, 2008.

3. ANDRADE, Manuel Correa de. A guerra dos cabanos. Rio de Janeiro: Conquista, 1965.

4. BOBBIO, Noberto. Dicionário de política. 5. ed. Brasília, Universidade de Brasília,1993.

5. CARNEIRO, Edison. O Quilombo dos Palmares. Coleção Brasiliana vol. 302. São Paulo: Editora Nacional, 1947.

6. CARVALHO, Marcus Joaquim Maciel de. Hegemony and rebellion in Pernambuco (Brazil), 1832-1835. Tese de Doutorado. Illinois: University of Illinois, 1985

XVII-XIX. In: Clio - Revista de Pesquisa Histórica - no. 25-2, Pernambuco: EDUFPE, 2007.

8. ESPÍNDOLA, Thomaz do Bom-Fim. A Geografia Alagoana ou descrição física, política e histórica da província das Alagoas. Maceió: Edições Catavento: 2001 [1871].

9. FREITAS, Décio. Os guerrilheiros do Imperador. Rio de Janeiro: Graal, 1978.

10. GOMES, Flávio; FERREIRA, Roquinaldo. A Miragem da Miscigenação In: Novos Estudos, no 80, CEBRAP, Março de 2008.

11. LIMA, Ivana Stolze. Cores, marcas e falas. Sentidos da mestiçagem no Império do Brasil. Rio de Janeiro: Arquivo Nacional, 2003.

12. LINDOSO, Dirceu. A utopia armada. Rebeliões de pobres nas matas do Tombo Real (1832-1850). Rio de Janeiro: Paz e Terra, 1983.

13. . Formação de Alagoas Boreal. Maceió: Catavento, 2000.

14._. Interpretação da Província. Estudo da cultura alagoana. Maceió: EDUFAL, 2005.

15. MONTEIRO. Hamilton de Mattos. Nordeste insurgente (1850 - 1890). São Paulo: Brasiliense, 1981. 
16. MORAES, Antonio Carlos Robert. O sertão: um "outro" geográfico. In: Terra Brasilis - Revista de História do Pensamento Geográfico no Brasil. Anos III-IV, no 4-5 - Território, Rio de Janeiro: 2002-2003.

17. MOREL, Marco. O período das regências (1831-1840). Rio de Janeiro: Zahar, 2003.

18. MOTA, Lúcio Tadeu.O Instituto Histórico e Geográfico Brasileiro e as propostas de integração das comunidades indígenas no Estado nacional.In:

http://www.dhi.uem.br/publicacoesdhi/dialogos/volume01/Revista\%20Dia logos/DI\%C1LOGOS09.doc(16/12/06).

19. NEVES, Frederico de Castro. Economia moral versus moral econômica (ou: o que é economicamente correto para os pobres?). In: Projeto História. Dossiê Cultura e Trabalho. nº 16, São Paulo: EDUC, fevereiro/ 1998.

20. PAMPLONA, Marco A. A historiografia sobre o protesto popular: uma contribuição para o estudo das revoltas urbanas. In: Revista Estudos Históricos, Rio de Janeiro, nำ17, 1996.

21. PUNTONI, Pedro. A guerra dos bárbaros. Povos indígenas e a colonização do sertão nordeste do Brasil, 1650 - 1720. São Paulo: Hucitec, 2002.

22. RELATÓRIO DO CAPITÃO-GENERAL JOSÉ CÉSAR DE MENESES. Idéia da população da Capitania de Pernambuco e das suas anexas, extensão de suas Costas, Rios e Povoações notáveis, agricultura, número de Engenhos, Contratos e Rendimentos Reais, aumento que estes tem tido \& desde o ano de 1774 em que tomou posse do Governador das mesmas Capitanias o Governador e Capitaim General... In: Annaes da Biblioteca Nacional do Rio de Janeiro, vol. XL (1918). Rio de Janeiro: Oficinas Gráficas da Biblioteca Nacional, 1923.

23.SCOTT, James Scott. Weapons of the weaks. Everyday forms of peasant Resistance. New Haven and London: Yale University Press, 1985.

24. Domination and the Arts of Resistance: Hidden Transcripts. New Haven and London: Yale University Press, 1990.

25. . Formas cotidianas da resistência camponesa. (Tradução: Marilda $A$. de Menezes e Lemuel Guerra). In: Raízes, Vol. 21, no 01, Campina Grande: jan.-jun./ 2002.

26. THOMPSON, E. P. Costumes em Comum. São Paulo: Cia. das Letras, 2005.

27. VERDONK, Adriano. Descrição das Capitanias de Pernambuco, Itamaracá, Parahyba e Rio Grande (Memória apresentada ao Conselho Político do Brasil (20 de maio de 1630) In: Revista do Instituto Histórico, Arqueológico e Geográfico de Pernambuco, ํㅡ⒌ Recife XXXIX, 1901.

\section{Fontes:}

28. Carta de Vicente Ferreira de Paula à Pinto Madeira Cf. Sessão de Manuscritos, I-32, 11, 2, em 08/10/1833. In: BN e Ministério da Guerra, IG1 94, em 09/01/1833 In: Arquivo Nacional - RJ (AN). 
29. PEREIRA, Inácio. Correspondência a Junta de Porto Calvo. Jacuípe, em 08/03/1823. In: Arquivo público de Alagoas (APA).

30. Relatório do presidente da Província de Alagoas, Rodrigo de Souza da Silva Pontes, em 12/01/1837 In:AN.

31. Relatório do presidente da Província de Alagoas, Rodrigo de Souza da Silva Pontes, em 06/01/1838. In: AN.

32. Relatório do presidente da Província de Alagoas, Agostinho Neves, em 09/05/1839. In: AN.

33. Relatório do presidente da Província de Alagoas, Souza Mello, em 04/02/1842. In: AN.

34. Relatório do presidente da Província de Alagoas, Antonio Manoel Campos Melo, em Março de 1846. In: AN.

35. Relatório do presidente da Província de Alagoas, Antonio Manoel Campos Melo, em 15/03/1847. In: AN. 